\title{
Terceirização no Processamento Final da Indústria Farmacêutica e Veterinária
}

\author{
Melissa Peron e Sá \\ José Vitor Bomtempo \\ Cristiane Quental
}

\section{Resumo}

Este trabalho tem como objetivo principal analisar o comportamento de empresas pertencentes ou ligadas às indústrias farmacêutica e/ou veterinária a respeito da compra e venda de serviços a terceiros, particularmente no processamento final de seus produtos. Realizou-se para este propósito uma pesquisa de campo com 226 empresas localizadas nas regiões sul e sudeste do país, por meio de questionários e entrevistas, com uma taxa de retorno de respostas de $37 \%$. A análise dos resultados da pesquisa de campo revelou um grande interesse, pela maior parte das empresas respondentes, na compra e/ou venda de técnicas pertencentes ao processamento final de produtos, constatando-se que a terceirização é tendência crescente na maioria das empresas, sendo considerados bons os resultados decorrentes do processo.

Palavras-chaves: terceirização; processamento final; indústrias farmacêutica e veterinária.

\begin{abstract}
This work aims mainly to analyse the behavior of pharmaceutical and/or veterinary firms about buying and selling services to third parties, specially in the final processing of their products. It was undertaken to this purpose a field research with 226 companies located in the south and southeast regions of Brazil, through questionnaires and interviews, resulting in a $37 \%$ returning of answers. The analysis of the results of the field research revealed a big interest, by most of the enterprises, in buying and/or selling of routine techniques belonging to the final processing of products, showing that outsourcing is an increasing tendency in most of the companies, being considered good the results of the process.
\end{abstract}

Key words: outsourcing; final processing; pharmaceutical and veterinary firms. 


\section{INTRODUÇÃO}

O tema terceirização tem estado em evidência no meio empresarial, acadêmico, jurídico e sindical por ser uma prática de flexibilidade organizacional na busca de especialização e racionalização de recursos.

A terceirização pode ser definida, segundo Giosa (1993, p. 14), como "um processo de gestão pelo qual se repassam algumas atividades para terceiros - com os quais se estabelece uma relação de parceria - ficando a empresa concentrada apenas em tarefas essencialmente ligadas ao negócio em que atua”.

A terceirização, ou prática de comprar externamente produtos e serviços necessários ao processo produtivo, tem sido crescente; atingiu serviços tradicionalmente executados por funcionários e com recursos da própria empresa. A discussão em torno do processo envolve a maneira como as empresas entendem e realizam a terceirização. Neste aspecto, a interação entre estas e seus fornecedores, visando ao estabelecimento de parcerias, e as atitudes das companhias em relação a todos os trabalhadores envolvidos no processo são questões fundamentais para o êxito.

A terceirização ganha importância no momento em que as empresas precisam racionalizar recursos, redefinir suas operações, funcionar com estruturas mais enxutas e flexíveis. Ela aparece, desse modo, como um dos instrumentos de auxílio à necessária reestruturação organizacional, ao incremento da produtividade $\mathrm{e}$ da competitividade e à busca da identidade e comprometimento com a vocação da empresa.

O presente trabalho examina a terceirização na indústria farmacêutica e veterinária, tendo como motivação o caso do novo complexo industrial de BioManguinhos. O Instituto de Tecnologia em Imunobiológicos da Fundação Oswaldo Cruz - Fiocruz, Ministério da Saúde, denominado Bio-Manguinhos, é o responsável pela produção e desenvolvimento tecnológico de vacinas humanas, insumos e reagentes para diagnóstico de doenças transmissíveis, utilizados pelo Programa Nacional de Imunizações - PNI (Leal, 1993).

A operacionalização do novo complexo industrial proporcionou um expressivo aumento da capacidade no processamento final de imunobiológicos ${ }^{(1)}$, gerando uma ociosidade nas etapas de envasamento, liofilização, recravação, fechamento, rotulagem e embalagem, que a Fundação Oswaldo Cruz tem amplo interesse em diminuir (Leal, 1993).

O investimento total na nova planta de Bio-Manguinhos é estimado em cerca de 
60 milhões de dólares; o centro de processamento final de imunobiológicos representa cerca de 50\% deste valor (Leal, 1993). Conseqüentemente, o preenchimento da capacidade ociosa, apresentada nos processos pertencentes ao processamento final, é fundamental para a viabilidade econômica do complexo.

O presente artigo tem como objetivo central analisar o comportamento de empresas pertencentes ou ligadas à indústria farmacêutica e veterinária a respeito da compra e venda de serviços de terceiros, particularmente nas etapas do processamento final de seus produtos.

O trabalho está organizado da seguinte forma: primeiramente (seção 2), serão apresentados os argumentos teóricos, que serviram de base para a realização do estudo. Posteriormente (seção 3), será apresentada a metodologia da pesquisa de campo realizada e, em seguida (seção 4), os seus resultados. As conclusões do trabalho serão mostradas na seção 5 .

\section{Argumentos Teóricos}

Drucker (1992) afirma que, até o final do século, as empresas irão sofrer uma reestruturação radical: seus tamanhos serão uma decisão estratégica; as atividades ou funções que não representarem a essência da missão serão subcontratadas. Assim, a terceirização passa a ser um caminho natural a ser seguido pelas empresas, na busca de um modelo de eficiência baseado em estruturas menores e mais ágeis.

A economia dos custos de transação se vem tornando um fértil campo de avanço do conhecimento econômico, por causa da crescente importância da questão fazer ou comprar, considerada a essência da terceirização.

Williamson $(1975,1985,1989)$ foi o autor responsável pela sistematização e aprofundamento das questões referentes ao assunto, previamente abordado em diversos artigos, tais como o de Coase (1937), considerado o criador das raízes da economia dos custos de transação, a partir de suas análises realizadas a respeito da existência da firma. Ao utilizar na análise econômica conceitos como racionalidade limitada, oportunismo, incerteza e especificidade de ativos, Williamson (1989) permite um avanço expressivo na compreensão dos problemas contratuais na economia, tanto intrafirmas como interfirmas.

Neste sentido, os contratos de terceirização podem ser interpretados como mecanismos de redução dos custos de transação, permitindo que relações antes internalizadas passem a ser externalizadas, situando-se em uma posição interme- 
diária entre a hierarquia (internalização da produção) e o mercado (não internalização).

Entretanto, no que se refere à pesquisa realizada, a lógica dos contratos e relações de terceirização deve ser traduzida na forma de um conjunto de fatores determinantes e restritivos que permitam os benefícios e problemas, decorrentes da terceirização, que incidem sobre as empresas.

Baseando-se em trabalhos de consultores, tais como Queiroz (1992), Giosa (1993) e Pagnoncelli (1993), em estudos já realizados sobre o tema e em relatos de algumas empresas, e levando-se em consideração as especificidades dos setores farmacêutico e veterinário, listou-se um conjunto de fatores determinantes ou benefícios $^{(2)}$ da terceirização. Os fatores considerados foram os seguintes: concentração de esforços (focalização), maior capacidade de adaptação às mudanças (flexibilidade), agilização (desburocratização), melhoria da qualidade, aumento da produtividade, maior competitividade, redução de custos, redução de imobilizado, liberação de espaço, aprimoramento tecnológico dos itens terceirizados, diminuição de riscos de obsolescência de equipamentos, economia de escala e redução de níveis hierárquicos.

Do mesmo modo, identificou-se o seguinte conjunto de fatores restritivos ou problemas encontrados na implantação da terceirização: resistências e conservadorismo (cultura e comportamento da empresa contratante), falta de envolvimento dos funcionários, dificuldade de integração das culturas da empresa e do fornecedor, não cumprimento das cláusulas contratuais acordadas, má escolha do fornecedor, não conformidade do produto ou serviço em relação à qualidade requerida pela empresa contratante, dependência excessiva do fornecedor, falta de parâmetros de custos internos, más conseqüências em função da falta de auditoria na empresa do fornecedor, custo de demissões, conflito com os sindicatos, barreiras fiscais e trabalhistas, medo da exposição de informações sigilosas ou segredos tecnológicos da empresa e medo da perda de poder por parte dos empresários.

Com base nos elementos citados, elaborou-se uma pesquisa de campo, cuja metodologia é apresentada na seção a seguir.

\section{Metodologia da Pesquisa de Campo}

A pesquisa de campo tem como objetivo analisar o comportamento de empresas pertencentes ou ligadas às indústrias farmacêutica e veterinária a respeito da 
comercialização de serviços à terceiros, particularmente na parte do processamento final de seus produtos.

A partir das respostas obtidas, pode-se avaliar a existência e condições de um mercado para o qual a Fiocruz poderia vender serviços ligados ao seu processamento final, devido à capacidade ociosa que o seu novo complexo industrial possui.

Para a escolha do universo, foram selecionadas, em catálogos e em anuários de associações de empresas atuantes nas indústrias farmacêutica e veterinária, as empresas que produziam medicamentos humanos (produtos farmacêuticos ou especialidades farmoquímicas humanas) e/ou defensivos animais (especialidades que cuidam da saúde e produtividade animal, englobando especialidades farmoquímicas veterinárias e produtos controladores de pragas nos rebanhos), e que teriam possibilidade de comercializar serviços ou produtos a terceiros. Adotou-se este procedimento, esperando-se que as empresas escolhidas nos catálogos possuíssem etapas pertencentes ao processamento final semelhantes ou iguais às do novo complexo industrial de Bio-Manguinhos. Nestes casos, estão incluídas as empresas que produzem injetáveis, medicamentos líquidos de até $30 \mathrm{ml}$ envasados em frascos e produtos envasados em bisnagas.

Em relação à localização das empresas, selecionaram-se as firmas situadas nas regiões sul e sudeste, em virtude de haver maior concentração de empresas nestas regiões, principalmente na sudeste, com ênfase em São Paulo.

Não houve restrições quanto ao tamanho das empresas nem quanto à origem do capital.

Este universo é constituído por 226 empresas, com grande diversidade entre si.

Os questionários foram endereçados, basicamente, aos gerentes de produção, farmacêuticos ou veterinários responsáveis das empresas selecionadas. Estes profissionais foram escolhidos em virtude de terem capacidade e condições de responder, adequadamente, às perguntas feitas.

Deve-se ressaltar que, para o envio dos questionários às empresas, elas foram divididas em quatro grupos:

. empresas que compram serviços de terceiros no processamento final;

. empresas que comercializam serviços a terceiros no processamento final;

. empresas que compram e vendem serviços a terceiros no processamento final;

. empresas que não comercializam nem vendem serviços a terceiros no processamento final. 
Os questionários foram enviados através do correio, no período de julho a agosto de 1996 , sendo obtida uma taxa de retorno de $37 \%$, ou seja, 84 respostas $^{(3)}$.

\section{Principals Resultados da Pesquisa de Campo}

Primeiramente, serão mostrados os resultados comuns a todos os grupos de empresas, a fim de se obterem conclusões gerais a respeito do conjunto total de empresas. A seguir, este procedimento será repetido para cada grupo de empresas, a fim de se extraírem conclusões específicas.

\section{Resultados Comuns as Empresas (total: 84 empresas)}

\section{Caracterização Geral das Empresas}

Quanto à compra e venda de serviços terceirizados no processamento final, têm-se 28 empresas que compram serviços, 17 que fornecem serviços, 6 que compram e vendem serviços e 33 empresas que não compram nem vendem serviços, ou seja, possuem somente produção própria.

A maior parte das empresas (68\%) atua somente no setor farmacêutico, a origem do capital é nacional (75\%), a faixa de funcionários predominante situa-se entre 20 e 99 empregados (41\%), a faixa de faturamento anual (1995) predominante situa-se entre R \$1 e R \$4 milhões (29\%): são, portanto, empresas de pequeno porte quanto ao número de funcionários e quanto ao faturamento anual, segundo critérios habituais de classificação quanto ao porte (Rais, Sebrae e Bndes). Dentre os setores já terceirizados, pelo próprio viés com que foram selecionadas as empresas pesquisadas, predomina o processamento final $(68 \%)$, seguido do transporte de produtos (52\%) e da segurança (45\%).

\section{Caracterização dos Processos e Produtos}

As linhas de produtos predominantes nas empresas são: soluções - orais ou nasais (74\%), seguida de injetáveis (64\%) e de comprimidos, drágeas ou cápsulas $(64 \%)$.

A maior parte das empresas (82\%) possui envasamento em vidros, seguido do envasamento em frascos plásticos (75\%). Em relação aos injetáveis, 52\% e 51\% das empresas possuem envasamento em ampolas e em frascos-ampolas, respectivamente. 
Todas as empresas realizam ou compram de terceiros os processos de envasamento, controle de qualidade, rotulagem e embalagem. Somente $18 \%$ das empresas realizam ou compram de terceiros a etapa de liofilização, enquanto $46 \%$ das empresas realizam ou compram de terceiros a inspeção automática. Isto ocorre porque os dois últimos processos mencionados são muito específicos, não sendo necessários para a realização do processamento final da maioria das empresas, em virtude da existência de poucos produtos liofilizados no mercado, além do alto custo do liofilizador e da máquina de inspeção automática.

A maior parte das empresas (65\%) trabalha com um turno de oito horas diárias, seguidas por dois turnos $(17 \%)$ e três turnos desta duração $(8 \%)$, respectivamente.

A maior parte das empresas possui os processos pertencentes ao processamento final compatíveis com as necessidades atuais ou inferiores a elas. Quando a capacidade é inferior às necessidades das empresas, estas recorrem à compra parcial ou total dos processos.

A maior parte das empresas (68\%) possui interesse em comprar ou em vender mais alguma etapa do processamento final. Dentre estas, 34\% têm interesse em comprar mais serviços, enquanto $40 \%$ desejam vendê-los e $26 \%$ querem realizar ambas as atividades. Observa-se, portanto, não só a presença de empresas interessadas na compra de serviços, mas também a presença significativa de empresas interessadas na venda de serviços a terceiros, havendo a possibilidade de estas últimas serem concorrentes diretas da Fiocruz, dependendo do serviço vendido.

No caso da compra de serviços de terceiros (34 empresas interessadas), as etapas predominantes a serem adquiridas são o envasamento (56\%) e a embalagem $(53 \%)$. Este resultado sugere a existência de um mercado no qual a Fiocruz poderia vender estes serviços.

No caso da venda de serviços a terceiros (38 empresas interessadas), a etapa predominante a ser fornecida é o envasamento (89\%). A liofilização é a etapa que as empresas têm menos interesse em fornecer, o que é bom para a Fiocruz, visto que terá poucos concorrentes neste mercado, podendo até ser dominante na venda deste processo às empresas interessadas.

\section{Empresas que compram Serviços de Terceiros no Processamento Final (total: 34 empresas) - Grupo 1}

\section{Caracterização quanto à Terceirização}

O processo de terceirização se iniciou há mais de cinco anos em 50\% das em- 
presas. Em $26 \%$ delas sempre houve terceirização e em $12 \%$ este processo se iniciou entre 3 e 5 anos atrás. Estes resultados indicam que o processo de terceirização não é recente na maior parte das empresas pesquisadas.

\section{Fatores Determinantes e Benefícios da Terceirização}

A Tabela 1 apresenta os resultados obtidos em relação à importância dos fatores determinantes da terceirização no processamento final das empresas.

\section{Tabela 1: Grau de Importância dos Fatores Determinantes da Terceirização no Processamento Final das Empresas \\ (total: 34 empresas)}

\begin{tabular}{|c|c|c|c|c|c|}
\hline \multirow{2}{*}{ Fatores } & \multicolumn{2}{|r|}{ Grau } & \multirow{2}{*}{$\begin{array}{c}\text { de } \\
\text { Baixo } \\
(\%)\end{array}$} & \multicolumn{2}{|l|}{ Importância } \\
\hline & $\begin{array}{l}\text { Alto } \\
(\%)\end{array}$ & $\begin{array}{c}\text { Médio } \\
(\%)\end{array}$ & & $\begin{array}{c}\text { Irrelevante } \\
(\%)\end{array}$ & $\begin{array}{l}\mathrm{S} / \mathbf{R}^{*} \\
(\%)\end{array}$ \\
\hline $\begin{array}{l}\text { Concentração de esforços na atividade central } \\
\text { da firma (focalização) }\end{array}$ & 58 & 24 & 3 & 9 & 6 \\
\hline Falta de espaço & 49 & 15 & 18 & 12 & 6 \\
\hline Melhor atendimento às neces. do cliente & 40 & 15 & 24 & 12 & 9 \\
\hline Maior competitividade & 38 & 12 & 32 & 6 & 12 \\
\hline Melhor qualidade do produto ou serviço & 37 & 21 & 15 & 18 & 9 \\
\hline Liberação de espaço & 34 & 18 & 15 & 24 & 9 \\
\hline Redução de custos fixos ou administrativos & 32 & 26 & 15 & 21 & 6 \\
\hline Aumento da produtividade & 31 & 24 & 24 & 15 & 6 \\
\hline $\begin{array}{l}\text { Diminuição de riscos de obsolescência } \\
\text { de equipamentos }\end{array}$ & 29 & 32 & 18 & 15 & 6 \\
\hline Redução de ativo imobilizado & 29 & 21 & 29 & 9 & 12 \\
\hline Aprimoramento tecn. dos itens terceirizados & 28 & 21 & 24 & 21 & 6 \\
\hline $\begin{array}{l}\text { Maior flexibilidade (capacidade da empresa } \\
\text { se adaptar às mudanças ambientais) }\end{array}$ & 21 & 38 & 26 & 6 & 9 \\
\hline Agilização (desburocratização) & 12 & 32 & 18 & 32 & 6 \\
\hline Redução de níveis hierárquicos & 3 & 12 & 29 & 50 & 6 \\
\hline
\end{tabular}

* $\mathrm{S} / \mathrm{R}=$ sem resposta.

A maioria das empresas considera que os fatores listados são de média a alta importância, com exceção da agilização (desburocratização) e da redução de níveis hierárquicos. Observa-se que a focalização na atividade central da firma e a falta de espaço foram os itens a que se atribuiu o maior grau de importância. A focalização tende a ser uma preocupação comum à maioria das empresas nos dias de hoje. Já a falta de espaço atinge principalmente as micro e pequenas empresas que, sem grande espaço físico para a produção em suas dependências, são obrigadas a recorrer a terceiros para a realização da produção e/ou acabamento da maioria de seus produtos. 
Dentre os benefícios obtidos com a terceirização predominam: melhoria da qualidade do produto ou serviço (56\% de respostas), liberação de espaço (53\%), focalização no negócio central da empresa (47\%) e maior capacidade de adaptação às mudanças - flexibilidade (44\%).

\section{Redução de Custos}

O grau de importância do processamento final no custo total da produção é variável. Assim, 21\% dos respondentes disseram que o processamento final possui uma importância inferior a $10 \%$ do custo total da produção, e $34 \%$ dos respondentes disseram que a importância do processamento final se situa entre 10 e $20 \%$ do custo total da produção.

O efeito da terceirização sobre os custos no processamento final pode ser visto na Figura 1.

\section{Figura 1: Faixa Percentual de Redução de Custos no Processamento Final após a Terceirização (total: 34 empresas)}

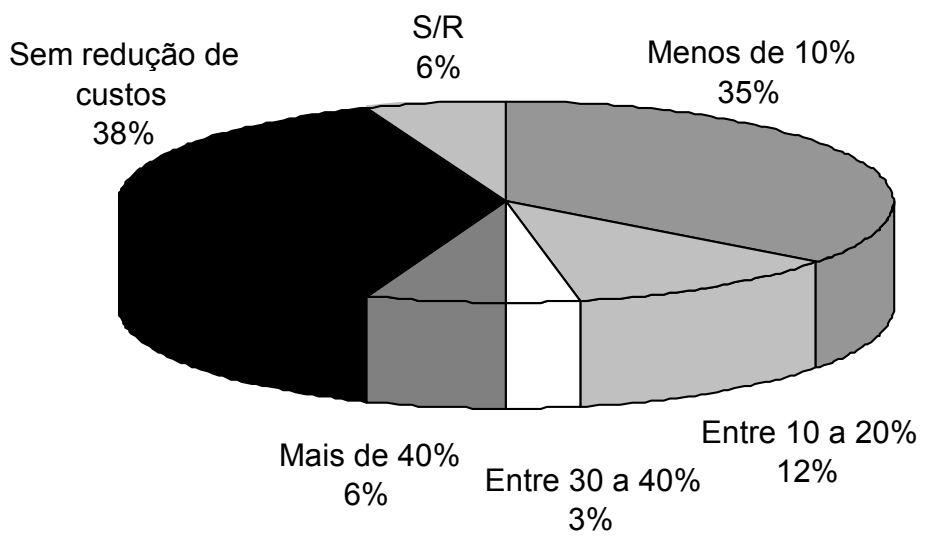

Observa-se que em 35\% das empresas houve uma redução de custos de menos de $10 \%$ em relação ao custo de realização do processo ou serviço internamente, e em 38\% não houve redução de custos. Destaca-se, portanto, que não há uma redução significativa de custos no processamento final da maior parte das empresas. 


\section{Fatores Restritivos e Problemas com a Terceirização}

A Tabela 2 apresenta os problemas encontrados na implantação da terceirização no processamento final das empresas.

\section{Tabela 2: Problemas na Implantação da Terceirização (total: 34 empresas)}

\begin{tabular}{lc}
\hline Problemas & \% \\
\hline Dependência excessiva do fornecedor & 56 \\
Dificuldade de integração das culturas cliente/fornecedor & 53 \\
Não-conformidade do produto ou serviço em relação à qualidade requerida pela & 41 \\
empresa & \\
Má escolha do fornecedor (negligência, incapacitação ou inexperiência) & 29 \\
Resistências e conservadorismo (cultura e comportamento da empresa) & 29 \\
Medo da exposição de informações sigilosas ou segredos tecnológicos da empresa & 24 \\
Não cumprimento das cláusulas contratuais como acordadas & 21 \\
Falta de parâmetros de custos internos & 18 \\
Más conseqüências em função da falta de auditoria na empresa do fornecedor & 15 \\
Não houve melhoria da qualidade com a redução de custos & 15 \\
Falta de envolvimento dos funcionários & 12 \\
Custo de demissões & 3 \\
Barreiras fiscais e trabalhistas & 3 \\
Medo da perda de poder por parte dos empresários & 3 \\
Conflito com os sindicatos & 0 \\
Outros problemas & 6 \\
Sem resposta & 6 \\
\hline
\end{tabular}

Observa-se que a dependência excessiva do fornecedor e a dificuldade de integração das culturas da empresa e do fornecedor foram considerados os problemas mais freqüentes na implantação da terceirização, com 56\% e 53\% de respostas, respectivamente. Há um pequeno número de fornecedores de produtos e serviços do processamento final no mercado; estes cobram preços elevados por seus serviços e entregam o produto, geralmente, após o prazo acordado, nem sempre com a qualidade desejada.

Apesar dos problemas com os fornecedores em relação ao preço e prazo de entrega dos serviços/produtos, o grau de confiança das empresas neles é em grande parte alto (47\%), seguido de médio (32\%) e de muito alto (15\%).

A Tabela 3 apresenta a importância dos itens avaliados no processo de escolha de um fornecedor de produtos/serviços do processamento final das empresas. 


\section{Tabela 3: Grau de Importância dos Itens Avaliados na Escolha de um Fornecedor de Produtos/Serviços \\ (total: 34 empresas)}

\begin{tabular}{|c|c|c|c|c|}
\hline \multirow[t]{2}{*}{ Itens } & \multicolumn{2}{|r|}{ Grau } & de Importância & \multirow[b]{2}{*}{$\begin{array}{l}\mathrm{S} / \mathrm{R} \\
(\%)\end{array}$} \\
\hline & $\begin{array}{l}\text { Alto } \\
(\%)\end{array}$ & $\begin{array}{l}\text { Médio } \\
(\%)\end{array}$ & $\begin{array}{l}\text { Baixo e Irrelevante } \\
(\%)\end{array}$ & \\
\hline Qualidade do produto ou serviço & 97 & 0 & 0 & 3 \\
\hline Prazo de entrega do produto ou serviço & 91 & 6 & 0 & 3 \\
\hline Capacidade instalada & 82 & 12 & 0 & 6 \\
\hline $\begin{array}{l}\text { Adoção de métodos de gestão fundamentados } \\
\text { na qualidade total }\end{array}$ & 73 & 12 & 6 & 9 \\
\hline $\begin{array}{l}\text { Flexibilidade para se adaptar às condições do } \\
\text { cliente (por exemplo: solicitações de última } \\
\text { hora) }\end{array}$ & 68 & 26 & 3 & 3 \\
\hline Preço do produto ou serviço & 62 & 35 & 0 & 3 \\
\hline $\begin{array}{l}\text { Flexibilidade na negociação dos preços e } \\
\text { condições de faturamento dos serviços }\end{array}$ & 59 & 26 & 12 & 3 \\
\hline $\begin{array}{l}\text { Lista de clientes e tipos de trabalhos } \\
\text { desenvolvidos }\end{array}$ & 50 & 32 & 12 & 6 \\
\hline Número de funcionários e técnicos habilitados & 46 & 28 & 18 & 8 \\
\hline Situação econômico-financeira do fornecedor & 44 & 32 & 18 & 6 \\
\hline Aprimoramento constante da tecnologia & 44 & 32 & 18 & 6 \\
\hline
\end{tabular}

Nota-se que, no processo de escolha de um fornecedor de produtos/serviços do processamento final, a maioria dos respondentes considerou os itens citados com um alto grau de importância, sendo que a qualidade dos produtos ou serviços foi considerada por todas as empresas respondentes como um item de alta importância.

Não há, internamente, trabalhadores de empresas terceiras na maior parte das empresas respondentes (68\%), nem envolvimento funcional com o fornecedor/ parceiro (88\%), caracterizando-se a completa individualidade e separação dos grupos cliente e fornecedor, no aspecto da localização de cada empresa.

Em relação à qualidade do produto final, a maioria dos respondentes $(53 \%)$ disse que realiza testes de controle da qualidade nas empresas contratada (do prestador/fornecedor) e contratante (do comprador/cliente), sendo que não existe o acompanhamento de técnicos da empresa contratante nos testes feitos dentro da contratada. Ou seja, os fornecedores realizam testes de controle de qualidade no produto final como parte da rotina de trabalho de suas empresas, e os compradores repetem os testes em suas dependências, a fim de checarem os resultados, para terem certeza da garantia e confiabilidade do produto.

O prazo de vigência de um contrato de terceirização situa-se na faixa de um a 
três anos em grande parte das empresas (44\%), sendo um período relativamente curto, mas razoável para o comprador verificar se o fornecedor é capaz de cumprir corretamente as cláusulas preestabelecidas, havendo renovação do contrato, caso ambas as partes concordem.

\section{Resultados e Perspectivas das Empresas no Processamento Final}

Os resultados decorrentes da terceirização no processamento final são considerados bons por $59 \%$ das empresas, razoáveis (26\%) e muito bons $(9 \%)$.

A maior parte das empresas (65\%) têm interesse em comprar ou em vender mais alguma etapa do processamento final, contra $32 \%$ que não possuem interesse e 3\% que não responderam a esta questão. Dentre as que querem comprar ou vender serviços ( 22 empresas), 55\% desejam comprar serviços do processamento final, $36 \%$ querem vender serviços e $9 \%$ desejam realizar ambas as atividades.

As etapas predominantes a serem compradas pelas empresas (14 empresas interessadas) são o envasamento de produtos (71\%), seguida da embalagem (57\%) e da liofilização (29\%).

Dentre as etapas a serem fornecidas pelas empresas, todas as interessadas (10 empresas $^{(4)}$ ) desejam vender o envasamento de produtos, seguido da rotulagem ( $60 \%$ das empresas). Metade das companhias deseja vender o controle de qualidade e a embalagem.

\section{Empresas que vendem Serviços a Terceiros no Processamento Fi- nal (total: 23 empresas) - Grupo 2}

\section{Caracterização quanto à Venda de Serviços a Terceiros}

O início do processo de fornecimento de serviços a terceiros no processamento final ocorreu, em $35 \%$ das empresas, entre três a cinco anos; em outros $35 \%$, há mais de cinco anos; não é, dessa maneira, um processo recente na maior parte das empresas.

O grau de confiança da empresa nos clientes é considerado alto por $65 \%$ dos respondentes, muito alto (26\%) e médio (9\%).

O prazo de vigência de um contrato de prestação de serviços a terceiros, no processamento final, situa-se, em $61 \%$ das empresas, na faixa de um a três anos. Este resultado foi seguido por $22 \%$ de empresas que não possuem um contrato formal, e por $9 \%$ cujo prazo de vigência é inferior a um ano. 


\section{Resultados e Perspectivas das Empresas no Processamento Final}

Os resultados decorrentes da prestação de serviços a terceiros no processamento final são considerados bons por $52 \%$ dos respondentes, muito bons (39\%) e razoáveis $(9 \%)$.

A maior parte das empresas (83\%) possuem interesse em comprar ou vender mais alguma etapa do processamento final, contra $17 \%$ que não têm interesse. Dentre as empresas pertencentes ao primeiro caso (19 empresas), 63\% desejam vender serviços a terceiros, enquanto $37 \%$ querem comprar e vendê-los.

Quanto ao interesse pela venda, o envasamento de produtos é a etapa de maior interesse (95\%), seguido da embalagem (74\%), rotulagem (63\%) e controle de qualidade (37\%). Somente $21 \%$ e $11 \%$ das empresas interessadas na venda de serviços a terceiros desejam vender as etapas de inspeção automática e liofilização, respectivamente. Este resultado está de pleno acordo com o obtido para o conjunto total de empresas, porém contrasta, parcialmente, com o obtido para o grupo 1, já que neste último a rotulagem é a segunda etapa de maior interesse pelas empresas, quanto à sua venda.

Dentre as etapas a serem adquiridas ( 7 empresas desejam comprar serviços de terceiros), a de liofilização é a mais desejada (43\%), seguida pelo envasamento de produtos e pela embalagem, em igual proporção (29\%). Este resultado opõe-se ao obtido para o conjunto total de empresas e para o grupo 1, visto que a etapa de liofilização não é a de maior interesse por parte destes grupos, quanto à sua compra.

\section{Empresas que não compram nem vendem Serviços Terceirizados no Processamento Final (total: 33 empresas) - Grupo 3}

\section{Caracterização quanto à Terceirização}

O aumento da produtividade é o principal fator determinante da terceirização considerado altamente importante por $53 \%$ dos respondentes ${ }^{(5)}$, ao contrário do observado no grupo das empresas que compram serviços de terceiros. A redução de custos fixos ou administrativos é altamente relevante para as empresas deste grupo ( $47 \%$ dos respondentes), contrastando, também, com o resultado obtido para o grupo 1 .

Os resultados mencionados anteriormente são explicados pela diferença de perfil entre estes dois grupos de empresas no que se refere ao faturamento anual (1995) das firmas. A maior parte das empresas do grupo 3, sendo de pequeno 
porte, realizam a terceirização pensando, basicamente, a curto prazo, no aumento da produtividade e na redução de custos, já que seus recursos econômico-financeiros são escassos. Para elas, a melhoria da qualidade do produto ou serviço é um fator secundário em relação à redução de custos, ao contrário do observado no grupo 1.

Em relação aos fatores considerados limitantes na implantação da terceirização, destacam-se os riscos embutidos na não-conformidade do produto ou serviço em relação à qualidade requerida pela empresa compradora (33\% de respostas) e na escolha do fornecedor (negligência, incapacitação ou inexperiência), com $30 \%$ de respostas.

A qualidade do produto ou serviço foi considerada por todas as empresas respondentes $(70 \%)$, como um item altamente importante na hora da escolha de um fornecedor de produtos e serviços, seguido pelo prazo de entrega de produtos e serviços $(61 \%)$.

\section{Perspectivas das Empresas no Processamento Final}

A maior parte das empresas (61\%) possuem interesse em comprar ou em vender alguma etapa do processamento final, contra $39 \%$ que não desejam realizar nenhuma destas atividades. Dentre os interessados (20 empresas), 35\% querem comprar serviços de terceiros, $25 \%$ desejam vendê-los e $40 \%$ querem realizar ambas as atividades.

A embalagem de produtos é a etapa de maior interesse (60\% de respostas) para quem deseja comprar serviços de terceiros (15 empresas interessadas), seguida do envasamento e do controle de qualidade (53\% de respostas, cada um) e da rotulagem ( $40 \%$ de respostas). Somente $7 \%$ das empresas desejam comprar a etapa de liofilização, o mesmo valendo para a inspeção automática.

O envasamento de produtos é a etapa de maior interesse (69\% de respostas) por parte das empresas que desejam vender serviços a terceiros (13 empresas), seguido da rotulagem e embalagem, com $46 \%$ de respostas, cada uma, e do controle de qualidade (38\% de respostas). Somente $15 \%$ das empresas desejam vender a liofilização, e $8 \%$ a etapa de inspeção automática.

\section{CONCLUSŐES}

Existe grande interesse, pela maior parte das empresas, na compra e/ou venda de processos pertencentes ao processamento final. 
Em relação à compra de serviços, as etapas de envasamento e embalagem de produtos são as de maior interesse, sugerindo existir um mercado no qual a Fiocruz poderia vender tais serviços, a fim de diminuir a sua capacidade ociosa nestes processos.

Nota-se, porém, que a Fiocruz poderá ter concorrentes neste mercado (empresas que têm interesse em vender estes serviços), principalmente no que se refere ao envasamento, caso o produto vendido seja um injetável ou seja envasado em bisnagas ou em frascos de até $30 \mathrm{ml}$ de capacidade, condições que a Fiocruz pode atender para prestar o serviço de envasamento às empresas interessadas. A liofilização é a etapa que as empresas têm menos interesse em fornecer, o que é bom para a Fiocruz, visto que poderá ter poucos concorrentes neste mercado; pode até ser dominante na venda deste processo às empresas interessadas.

A focalização na atividade central das empresas e a falta de espaço são os principais fatores determinantes da terceirização, considerados altamente importantes pela maior parte das empresas que compram serviços de terceiros. A falta de espaço atinge principalmente as micro e pequenas empresas. Este resultado está de acordo com os benefícios já alcançados por grande parte das empresas: a melhoria da qualidade do produto ou serviço realizado, obtida provavelmente com a focalização; a liberação de espaço, mediante a terceirização de serviços relacionados a produtos que não são o carro chefe de vendas das empresas.

O processamento final possui um grau variável de importância no custo total da produção. Entretanto nossos resultados comprovam que o fator redução de custos não é o mais importante na terceirização no processamento final das empresas, não tendo ocorrido redução significativa de custos no processamento final da maior parte das empresas após o processo de terceirização.

Observa-se, também, que as empresas que compram serviços de terceiros estão considerando a melhoria da qualidade do produto ou serviço como fator mais importante do que a redução de custos fixos ou administrativos. Este resultado interessante pode ser, ressalvadas as particularidades do caso estudado, uma indicação de que os clientes estão mais conscientes de seus direitos e mais exigentes quanto à qualidade dos produtos e serviços requeridos. Convém lembrar que a maior perda que uma empresa pode ter é a de um cliente, por não estar satisfeito com os serviços e atendimento do fornecedor.

A qualidade e o prazo de entrega do produto ou serviço pertencente ao processamento final são os itens mais relevantes na escolha de um fornecedor, evidenciando a importância de as empresas possuírem produtos de boa qualidade e de cumprirem os seus prazos de entrega, requisitos fundamentais para a sobrevivência e lucratividade de qualquer empresa na década atual. Este resultado está 
de acordo com o obtido em relação à realização de testes de controle de qualidade na empresa contratada (do prestador/fornecedor de serviços) e contratante (do comprador/cliente), fato que assegura a garantia e confiabilidade do produto. Observa-se que o preço do produto/serviço (fator relacionado à redução de custos nas empresas) não é, no caso examinado, o principal item avaliado na escolha do fornecedor, dando lugar à qualidade do produto ou serviço, como verificado anteriormente, a partir dos resultados de outras questões.

Os resultados decorrentes da terceirização ou prestação de serviços a terceiros no processamento final são considerados bons pela maior parte das empresas.

No que se refere à Bio-Manguinhos, algumas considerações devem ser feitas, visando à estratégia de conquista de maior fatia de mercado na venda de processos e serviços a terceiros. Primeiramente, Bio-Manguinhos deve procurar vender seus serviços para as empresas públicas e privadas interessadas, dada a existência de mercado para esta venda, como detectado na pesquisa de campo.

A Fiocruz deve, também, procurar envasar produtos de outras empresas, quando as máquinas não estiverem sendo utilizadas em benefício próprio, já que não é possível a existência de mais de um turno de trabalho nas etapas de liofilização e envasamento. $\mathrm{O}$ aumento da capacidade de venda dos processos de inspeção automática, rotulagem e embalagem pode ocorrer por meio da realização de dois ou três turnos de trabalho, visto que é possível a existência de mais de um turno de trabalho nestes processos.

Como a Fiocruz não possui um setor específico de marketing e vendas, essa estratégia é essencial para o seu sucesso na venda de serviços. Bio-Manguinhos deve procurar identificar seus mercados e as necessidades dos clientes, a fim de realizar serviços e produtos adequados, criando canais de distribuição e campanhas de marketing para a divulgação da venda de serviços às empresas interessadas, em revistas farmacêuticas especializadas, além de realizar a pesquisa de marketing e a análise de vendas, para acompanhar seus mercados.

\section{NOTAS}

${ }^{1} \mathrm{O}$ processamento final dos produtos ocorre após as etapas de síntese e formulação dos mesmos, englobando as etapas de envasamento, liofilização, recravação, fechamento, controle de qualidade, inspeção automática, rotulagem e embalagem de produtos.

${ }^{2}$ Os fatores determinantes, quando concretizados nas empresas, tornam-se benefícios.

${ }^{3}$ Desse total, obtiveram-se 78 questionários respondidos através do correio ou fax e 6 respostas através de visitas. 
${ }^{4}$ Deve-se notar que, quando se analisam, separadamente, as empresas que querem comprar serviços (14 empresas) e as interessadas na venda de serviços (10 empresas), a soma destes grupos supera em 2 unidades (número de empresas que desejam comprar e vender serviços) a análise global das empresas (22 empresas): no último caso, não se está considerando o que cada empresa deseja realizar em relação à compra e/ou venda de serviços a terceiros.

${ }^{5}$ Somente as empresas interessadas na compra de serviços de terceiros (15 empresas) é que responderam a esta questão.

\section{RefERÊNCIAS Biblográficas}

COASE, R. H.

The nature of the firm. Econômica, v. 4, n. 16, p. 386-405, Nov. 1937.

DRUCKER, P. F.

Managing for the future : the 1990s and beyond. New York: Truman Talley Books/Dutton, 1992.

\section{GIOSA, L. A.}

Terceirização : uma abordagem estratégica. São Paulo : Pioneira, 1993.

LEAL, M. L. F.

Institute of technology on immunobiologicals Bí Manguinhos - Oswaldo Cruz Foundation. Rio de Janeiro, 1993.

PAGNONCELLI, D.

Terceirização e parceirização : estratégias para o sucesso empre- sarial. Rio de Janeiro : D. Pagnoncelli, 1993.

QUEIROZ, C. A. R. S. DE.

Manual de terceirização : onde podemos errar no desenvolvimento e na implantação dos projetos e quais são os caminhos do sucesso. 3. ed. São Paulo : STS, 1992.

WILLIAMSON, O. E.

Markets and hierarchies : analysis and antitrust implications. New York : Free Press, 1975.

The economics institutions of capitalism : firms, markets, relational contracting. New York : Free Press, 1985.

Transaction cost economics. In: SCHAMALENSE, R.; WILLIG, R. D. Handbook of industrial organization. North Holland : Elsevier Science, 1989. v.1. cap. 3. 